\title{
Bronchiolitis obliterans with obstructive pulmonary disease
}

INSERM

\section{Source}

INSERM. (1999). Orphanet: an online rare disease and orphan drug data base.

Bronchiolitis obliterans with obstructive pulmonary disease. ORPHA:1303

Bronchiolitis obliterans syndrome (BOS) is a lung disorder that is mainly associated with

chronic allograft dysfunction after lung transplantation and that is characterized by

inflammation and fibrosis of bronchiolar walls that reduce the diameter of the

bronchioles and result in progressive and irreversible airflow obstruction. 